\title{
Colégio Estadual Quilombola Diogo Ramos: olhares sobre educação na Comunidade de João Surá
}

\author{
Quilombola State College Diogo Ramos: views on education in the community of João \\ Surá
}

\author{
Fabiane Moreira ${ }^{1}$ \\ Sanciaray Yarha Silva da Rosa ${ }^{2}$
}

\begin{abstract}
Resumo
O presente documento refere-se ao projeto sobre Educação Quilombola no Estado do Paraná, desenvolvido pelo grupo de pesquisa Joana de Andrade, que tem como objetivo analisar a efetivação de políticas públicas de educação escolar quilombola no estado, além de compreender os processos de produção de conhecimento intercultural baseado na integração da comunidade quilombola e as práticas pedagógicas. Para tanto, realizou-se um levantamento bibliográfico acerca dessa temática, bem como pesquisa de campo desenvolvida no Colégio Estadual Diogo Ramos, tendo como metodologia a etnografia e o uso de caderno de campo. Com isso foi possível conhecer de perto a realidade da Comunidade de João Surá (PR), e também os processos de escolarização no território quilombola.
\end{abstract}

Palavras-chave: Educação escolar quilombola. Comunidade quilombola. Educação quilombola.

\begin{abstract}
:
This document refers to the Quilombola Education Project in the State of Paraná, developed by the research group Joana de Andrade, whose objective is to analyze the effectiveness of public policies for quilombola schooling in the state, as well as to understand the processes of production of intercultural knowledge based on the integration of the quilombola community and pedagogical practices. For that, a bibliographical survey was carried out on this subject, as well as field research developed at Diogo Ramos State College, using as methodology the ethnography and the use of field books. With this, it was possible to know closely the reality of the Community of João Surá (PR), as well as the schooling processes in the quilombola territory.
\end{abstract}

Keywords: Quilombola school education. Quilombola community. Quilombola education.

\section{Introdução}

A cultura quilombola, por se constituir em um espaço de trocas e compartilhamentos simbólicos-afetivos e se consolidar em relação a um contexto político, cultural e social

\footnotetext{
${ }^{1}$ Mestranda do Programa de Pós-Graduação em Educação da Universidade Federal do Paraná e integrante do Grupo de Pesquisa e Extensão Joana de Andrade. E-mail: fabianemoreira05@gmail.com

${ }^{2}$ Graduanda do curso de Pedagogia da UFPR e integrante do Grupo de Pesquisa e Extensão Joana de Andrade.

E-mail: sancypedagogia@gmail.com
} 
específico, destaca as especificidades dos indivíduos que a compõem. É com contumácia que busca preservar elementos culturais históricos que permitem com que os sujeitos se reconheçam como parte da história de seu território. Nesse sentido o espaço escolar inserido ou que recebe quilombolas pode ser também um espaço estratégico de reforço da cultura quilombola e preservação do seu modo de vida. Em 2017 na Comunidade Quilombola João Surá, desenvolveram-se atividades do Curso de Formação Pré-Acadêmica para ingresso à pósgraduação proposta pelo NEAB da UFPR, numa iniciativa de políticas de ações afirmativas para aumentar ingresso de alunos negros, pobres, indígenas, quilombolas e trans na Pósgraduação. Esse curso que estava acontecendo em Curitiba ganhou uma turma na comunidade, sendo o primeiro curso do gênero a ser realizado em um quilombo, tinha como objetivo auxiliar uma turma de alunos quilombolas para ocuparem o espaço universitário. Trata-se de uma demanda da própria comunidade, que demonstra o seu envolvimento não apenas com a educação básica, mas que também quer se ver representada no espaço dentro da academia e falar por si própria. O curso foi sediado no Colégio estadual Quilombola Diogo Ramos, que está localizado dentro do território da comunidade, e contou com participação da equipe de professores e funcionários do colégio e também de outras pessoas da comunidade que tinham interesse em aprimorar conhecimentos técnicos sobre pesquisa.

O grupo de Pesquisa Joana de Andrade, que há quatro anos desenvolve pesquisas sobre quilombo, educação e território em João Surá também participou dessa iniciativa, oferecendo projetos de intervenção com os estudantes da educação infantil, ensino fundamental e médio durante a execução do curso, de tal forma que seria possível observar e participar com maior envolvimento, desde o fazer pedagógico até de que maneira a comunidade desenvolve e abraça a escola. Desse modo, abre-se a possibilidade de compreender a interculturalidade do saber tradicional de uma comunidade que há mais de 200 anos vem enfrentando ameaças de destruição do seu modo de vida, seja ela através da expropriação fundiária vinda por latifundiários ou por iniciativas do governo de isolamento dos território tradicionais na construção de parques e reservas de preservação, ou através do apagamento de sua história de luta e resistência, através de conflitos sociais gerados por um modelo educacional eurocentrista que visa a manutenção do capitalismo, que já se comprovou nocivo não só para comunidades tradicionais, mas para a sociedade como um todo. Através das intervenções conseguimos presenciar o movimento que os quilombolas construíram com o colégio para ensinamento dos seus conhecimentos em consonância com a proposta pedagógica de ensino formal aqui relatados. 
Este artigo tem como objetivo buscar refletir sobre aquilo que é proposto não apenas pelo currículo do colégio, mas também pela LDB 9394/96 que traz como consideração que: “o ensino da História do Brasil deve levar em conta as contribuições das diferentes culturas e etnias para a formação do povo brasileiro, especialmente das matrizes indígena, africana e europeia" (BRASIL, 1996). Existem outros documentos norteadores a respeito da educação quilombola, como as Diretrizes Curriculares para a Educação Quilombola (MEC 2012). Buscamos observar as metodologias que consideram as representações da vida quilombola e a valorização das referências históricas. A metodologia que desenvolvida é a etnografia que tem suas bases na antropologia utilizando a observação e levantamento de hipóteses, onde o etnógrafo busca descrever na sua interpretação, o que está ocorrendo no contexto pesquisado. Segundo Mattos:

A etnografia é um processo guiado preponderantemente pelo senso questionador do etnógrafo. Deste modo, a utilização de técnicas e procedimentos etnográficos, não segue padrões rígidos ou pré-determinados, mas sim, o senso que o etnógrafo desenvolve a partir do trabalho de campo no contexto social da pesquisa (MATTOS, 2011, p.50).

Em outras palavras, a etnografia é o estudo descritivo da cultura dos povos, sua língua, suas crenças, hábitos etc. Por isso em sua maioria, a metodologia exige do pesquisador a presença em campo. Como registro escrito optamos pelo uso do caderno de campo, ele tornase indispensável e uma ferramenta que contém os registros do pesquisador, observações e reflexões que surgem durante a pesquisa. Também fizemos uso do registro fotográfico para melhor ter noção do espaço físico do território onde pesquisamos, e dos momentos vivenciados em campo.

Segundo a Associação Brasileira de Antropologia (ABA, 1994), a categoria "remanescentes de quilombos" deve compreender todos os grupos que desenvolveram práticas de resistência na manutenção e na reprodução de seus modos de vida característicos em um determinado lugar, cuja identidade se define por uma referência histórica comum construída a partir de vivências e de valores partilhados. Partindo desta perspectiva, é preciso compreender que a educação formal pode assumir um papel de singularidade no território quilombola. Desde o período escravocrata a educação escolar se torna um ponto de emancipação para a população negra. Nesse sentido, é preciso pensar no reconhecimento da multiculturalidade dentro da educação formal, processos educacionais que incorporam o reconhecimento dos sujeitos que protagonizam a vida nos territórios quilombolas. Apesar da educação escolar quilombola e 
educação quilombola poderem ser caracterizadas de diversas maneiras, em vários momentos elas se encontram, o que faz com que o conceito da relação escola e comunidade se fortaleça. Segundo Max Silva da Rocha e José Bezerra da Silva:

É característica da Educação Escolar Quilombola a discussão em torno da demarcação do território quilombola enquanto espaço educativo. Sabemos, porém, que pouquíssimas comunidades têm seu território demarcado, e os ruralistas têm se movimentado no sentido de impedir as demarcações. $\mathrm{O}$ Estado, por sua vez, se utiliza de grande morosidade para viabilizar esse direito. Por outro lado, o agronegócio cresce assustadoramente e com o beneplácito financeiro do governo federal (ROCHA; SILVA, 2016 p.90).

Toda iniciativa de fortalecimento das lutas das comunidades pela titulação do seu território, contra as barragens, contra a monocultura que danifica o solo e nascentes e também a favor do bem viver tem como objetivo a transformação social, visando o bem comum e um modelo de sociedade sustentável. Nesse sentido, fazer educação nos espaços comunitários não pode estar dissociado da luta territorial e das demandas da sua comunidade. Experimentamos por séculos um modelo educacional voltado para individualização e desumanização dos sujeitos "em todos esses aspectos, pode-se discernir um conjunto de suposições e problemas comuns que indicam sua linhagem eurocêntrica comum" (QUIJANO, 2007, p.97), o que cada vez vem sendo mais contestado por diferentes pensadores e pesquisadores, como a crítica decolonial ao pensamento eurocêntrico as pedagogias insubmissas que divergem da lógica eurocêntrica e excludente de ensino. Mas a busca pela construção de pedagogias insubmissas e emancipadoras visando a educação como prática da liberdade ainda não são maioria no espaço educacional e precisam com urgência ocupar este espaço, transformando o ensino em algo mais plural e emancipador que atinja de fato seus sujeitos atuantes.

Hoje, a luta contra a exploração / dominação implica, sem dúvida, em primeiro lugar, a luta pela destruição da colonialidade do poder, não só para acabar com o racismo, mas por causa de seu eixo de status articulada-dor o padrão universal capitalismo eurocentrada (QUIJANO, 2007, p.124).

Entende-se que precisamos de um modelo que aborde essas questões, que pense numa educação antirracista e, ao fazê-lo, estará em confronto com pensamentos da lógica capitalista, buscando um modelo mais humanitário dentro das escolas, um modelo que abrace a seus educandos em todo processo de aprendizagem e que não se desvincule do que a comunidade deseja em sua coletividade. A experiência vivenciada no colégio nos proporcionou observar na prática uma educação de cunho emancipador que consegue confluir o conhecimento ocidental 
com os conhecimentos da comunidade, dando preferência e ênfase nos ensinamentos ancestrais dos quilombolas e da cultura afro brasileira.

\section{Colégio Estadual Quilombola Diogo Ramos - Na Luta Pela Educação}

Ao chegar na comunidade, logo na entrada nos deparamos com uma placa colorida que dizia: "Bem-Vindos/as à comunidade Quilombola de João Surá". Ao lado havia uma estreita estrada de chão com algumas casas e muitas árvores compondo a paisagem. Por essa estrada seguimos até o Colégio Estadual Diogo Ramos. Fomos recebidas com muito ânimo e entusiasmo por todos que estavam presentes no colégio, o sentimento era de acolhimento, apesar não conhecer ninguém recebemos muitos sorrisos e percebemos o sentimento de orgulho e pertencimento das pessoas com seu território. Fomos convidadas a realizar uma das trilhas que a comunidade preserva, essa em especial traça a rota que os quilombolas usaram para se refugiar, principalmente na convocação para guerra do Paraguai, onde muitas frotas passavam pela região do vale até chegar nos frontes de batalha. Não somente os escravizados utilizam a trilha, mas também indígenas que foram obrigados a atuar nesse conflito e hoje não são lembrados como parte importante desse e de outros conflitos pelos registros históricos. Essa aula de história podemos fazer enquanto seguíamos a trilha em direção a uma antiga construção de barro, com mais de 100 anos de existência, onde existia um fogão de lenha que os quilombolas construíram no meio da mata enquanto se escondiam das frotas imperiais. A parte mais interessante do passeio é que o guia que contava as histórias, mostrava o caminho e os bichos que encontrávamos no meio do percurso era um dos estudantes do ensino fundamental do colégio, que ensinou muito mais em poucas horas do que podemos aprender nos livros didáticos atuais. 


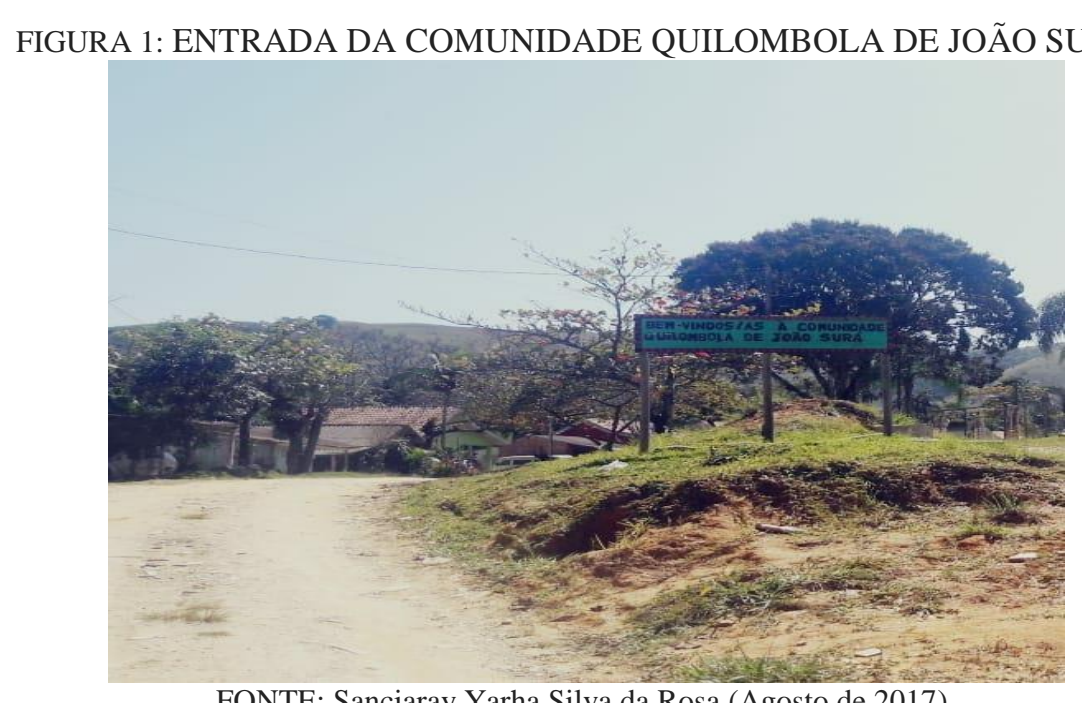

FONTE: Sanciaray Yarha Silva da Rosa (Agosto de 2017)

A comunidade de João Surá está localizada a 50 quilômetros do município de Adrianópolis (PR), região do Alto Vale do Ribeira do Iguape, na fronteira entre os estados do Paraná e São Paulo, nas áreas envolvidas pela confluência do Rio Ribeira com o Rio Pardo. Tem mais de 200 anos de existência e aproximadamente 50 famílias. Dentro deste território localiza-se o Colégio Estadual Quilombola Diogo Ramos, que atende aproximadamente 40 alunos, em sua maioria estudantes do ensino fundamental. Durante o período em campo, foi possível perceber que a comunidade e o colégio têm uma interação intensa. Os portões ficam abertos e de acesso livre, sendo um espaço de todos da comunidade, com o qual existe um sentimento de pertencimento expressado pela comunidade e alunos. A troca de saberes entre os mais velhos e mais novos também ficou evidente durante o processo de pesquisa. Durante nosso trabalho de campo pudemos presenciar algumas vezes a valorização das anciãs da comunidade em atividades comemorativas e formais do colégio, como ocorreu numa mesa com as lideranças da comunidade resgatando a história e registros da própria comunidade em comemoração ao dia dos professores em outubro, na qual estavam as primeiras professoras da comunidade, valorizando os saberes que fazem parte da cultura e história da comunidade. Assim podemos dizer que:

Buscar o conselho dos mais velhos como bússola aos caminhos do aprendizado demonstra a potente interpelação da proposta de educação escolar quilombola. A revés dos manuais que historicamente carregavam conteúdos eurocêntricos, os padrões civilizatórios africanos tomam centralidade na educação (BORBA e MOREIRA, 2018, p.162). 
Sendo assim, as pessoas mais velhas da comunidade expressam suas lembranças realizando uma releitura de seu passado, tendo a possibilidade de refletir sobre determinados momentos e detalhes importantes de sua história. Reinventando sua identidade, a memória quilombola dos mais velhos permite uma nova versão da história contada do ponto de vista daqueles que detém detalhes ricos que foram silenciados pela sociedade colonizadora e usurpados para fins lucrativos, como o conhecimento sobre ervas medicinais e outras plantas que é apropriado por grandes indústrias farmacêuticas, pois o "conhecimento dos indígenas não valem a lei escrita, mas servem para a acumulação capitalista desenfreada" (GARCÉS, 2007, p.231). Assim, se valem do conhecimento tradicional das comunidades, em especial das quilombolas, que têm sua identidade desvalorizada.

Por isso, compreende-se que os saberes interculturais dos mais velhos, além de ser valorizado como fonte histórica, é também parte da proposta curricular do colégio, que consegue confluir os conhecimentos ocidentais com os conhecimentos seculares da própria comunidade, não só em eventos comemorativos do calendário escolar, mas em outras questões, como o uso de ervas medicinais e a confecção de peneiras, usadas na agricultura da comunidade e que foram trazidas para o interior do Colégio.

A experiência com a confecção das peneiras foi algo interessante de observar, pois a princípio as crianças e os adultos presentes compreendiam que existia uma complexidade, mas não sabiam ao certo em que grau. Foi somente na prática que se pode perceber os elementos de lógica matemática espacial e de geometria envolvidas na confecção dos artefatos. Seu Paulico aos poucos ia trançando para fazer as peneiras com muita naturalidade. A atividade juntou não só as disciplinas de matemática e história, mas também de geografia e artes, trabalhando conceitos de cada uma das disciplinas com os alunos como a origem da prática de fazer peneiras na escola, a utilidade das peneiras na agroecologia, a arte desenhada pelos traçados artesanais e outros pontos que puderam ser explorados na vivência com os mais velhos da comunidade, numa atividade que em outros modelos escolares poderia não ser considerada atividade formativa. Para nós, pesquisadoras, foi possível perceber também nesse momento a interação da comunidade com os mais velhos, a importância dos trabalhos manuais para a comunidade e a valorização deste trabalho.

A educação escolar quilombola, como modalidade, tem pouco tempo de vigência no Ensino Nacional. As Diretrizes Curriculares Nacionais Para Educação Escolar Quilombola DCNEEQ foram homologadas apenas em 2012, resultado da luta da população negra. Sua estrutura tomou como base a proposta pedagógica criada em 2010 no estado do Paraná, que 
visava a educação escolar quilombola, sendo pioneiro no ensino dessa modalidade e contribuindo para a propagação nacional da formalização do ensino dedicado a quilombolas, com um currículo diferenciado e valorização desse modo de vida tradicional. O colégio Diogo Ramos foi parte importante desse processo histórico de formulação dessas pedagogias voltadas aos quilombolas, e depois de quase uma década do colégio e da formalização desta modalidade, conseguimos observa e vivenciar, através do trabalho realizado em campo na comunidade, que o currículo do colégio contempla as Leis 10.639/2003 e 11.645/2008. O Colégio Estadual Diogo Ramos busca a implementação das leis através de seu currículo, selecionando elementos culturais que fazem parte da composição da comunidade a qual o Colégio está inserido.

A educação quilombola, portanto, torna-se eficiente e necessária a seu povo na medida em que suas condições estruturais e pedagógicas possam proporcionar uma prática educacional condizente com aquilo que é previsto nas Diretrizes Curriculares. A sua eficiência é o que contribui para o empoderamento das crianças e jovens quilombolas, algo fundamental para continuarem na luta pela garantia de permanência em seu território, o que, consequentemente, contribui na melhoria das condições de vida e ensino dessas comunidades (CAMPOS, GALINARI, 2017, p.215).

O Colégio Diogo Ramos atende alunos da comunidade João Surá e outros alunos de comunidade vizinhas. Esses alunos, antes da criação do colégio, tinham que percorrer um trajeto de aproximadamente $20 \mathrm{~km}$ todos os dias para frequentar as aulas na Escola Estadual Porto Novo, colégio mais próximo que atende alunos quilombolas. Os perigos que enfrentavam nesse percurso levaram à mobilização dos pais e da comunidade como um todo para reivindicar um colégio na comunidade. Essa realidade ainda se faz presente em outras comunidades do vale ou de outras regiões, onde a única opção é frequentar escolas situadas fora do território de quilombola. Nesse sentido, é importante que não só as escolas inseridas dentro do território quilombola, mas também as que atendem esses alunos, ponderem as questões que envolvam a comunidade. A DCNEEQ estabelece que escolas não inseridas no território, mas que também atendem alunos quilombolas, precisam de uma organização curricular diferenciada que contemple as demandas desses alunos, como ensino de sua cultura e valorização do modo tradicional de vida dos quilombolas, além de atender a normativa padrão das Leis 10.639/03 e 11.645/08, sendo assim:

A passagem das crianças quilombolas pela escola deve prioritariamente, fortalecê-las na possibilidade de luta por direitos ainda negados aqueles/as que cartografam os mapas da região sul e do resto do país com cartografias imprecisas, paradoxais, de carências e abundâncias (NUNES, 2016, p. 172). 
Essa reflexão está intrinsecamente ligada às demandas e lutas pelo território. No cenário político atual, em que o conflito com latifundiários é cada vez mais constante nas questões fundiárias, as comunidades quilombolas se organizam para garantir seu território. Entender a realidade das comunidades e fortalecer esses alunos é também papel da instituição, o que só é possível com a interação da comunidade no ambiente escolar. Se a comunidade não se vê presente nesse espaço, outros aspectos da aprendizagem poderão ficar defasados para esses alunos, assim como Freire (1996) problematiza no tocante do fazer educação onde "atitude dialogal à qual os coordenadores devem converter-se para que façam realmente educação e não 'domesticação' [...] este esforço sério de capacitação deverá estar acompanhado permanentemente de um outro". Nesse sentido as escolas que atendem alunos quilombolas, seja ela dentro ou fora do território, precisa, estar em diálogo construtivo com a comunidade para o fazer pedagógico ser realmente educador. Segundo Edimara Gonçalves Soares:

A comunidade quilombola é um importante espaço pedagógico onde podem e devem ser levantadas e problematizadas questões sobre vários e diferentes elementos que constituem a base da subjetividade e das experiências formativas dos/as educandos/as (SOARES, 2010 p.44).

Nesse sentido vale destacar a ação da direção, do setor pedagógico e do quadro docente do Colégio Estadual Quilombola Diogo Ramos, pois a todo momento estavam valorizando o trabalho desenvolvido pelos estudantes. Existe uma grande parceria entre estudantes e demais funcionários da escola, trazendo e reforçando o conceito de comunidade na qual eles estão inseridos. Foi possível perceber, durante a vivência na comunidade, que existem diversas estratégias para que se mantenha uma horizontalidade dentro da escola, ou seja, o professor não é o único detentor do saber, o colégio não pertence apenas a direção ou outras figuras de autoridade, mas a todos que usufruem daquele espaço, inclusive da comunidade ao seu redor, o que possibilita aos estudantes uma maior liberdade de se expressar.

\section{Projeto de intervenção com os estudantes de Ensino infantil e Fundamental I}

Durante as visitas de campo foi possível ter um contato maior com a Maria, que era aluna do pré-pós e também professora na Escola Municipal Rural de João Surá, que se localiza ao lado do colégio Diogo Ramos. Apesar da escola ter características e públicos diferentes, pode-se notar que existem várias questões dentro da escola que coincidem com a do colégio 
Diogo Ramos, estruturas essas que se encontram alinhadas ao entendimento do modo de viver da comunidade, com a cultura e ancestralidade de seu território.

A escola conta com um espaço tímido, dois banheiros, um parquinho, cozinha e uma sala que é multisseriada, uma pequena varanda que tem vista para um terreno com um gramado que as crianças também usam para brincar. Apesar de ofertar pouca estrutura, percebe-se um grande envolvimento da Maria, que era a única professora da escola, e dos alunos com aquele espaço. Existem espalhadas pela sala decorações de barro feitas por ela e, em nossa visita, ela mostrou que estava ensinando as crianças a também criarem seus objetos. As crianças tinham um cuidado com a organização do espaço e foi possível perceber uma grande autonomia e liberdade em gerenciar o espaço entre as crianças, nada era engessado, o que possibilita na existência de uma grande troca de saberes entre a Maria e os alunos.

Outra questão que chamou bastante atenção foi o contato com a leitura que as crianças tinham, não existia uma hora fixa para esse momento, era algo que partia do desejo das crianças, pois elas tinham sempre à disposição os livros. As brincadeiras também foram algo de bastante destaque. Nas escolas urbanas, percebemos que o espaço do lúdico acaba sendo sufocado, enquanto o brincar na rotina desta escola tem uma centralidade que se faz fundamental. Muitas brincadeiras estão ligadas à rotina da comunidade e o seu modo de viver como também à sua ancestralidade, pois existe uma preocupação com este resgate, ao mesmo tempo em que novas brincadeiras surgem, o adultocentrismo torna-se praticamente nulo neste espaço.

Para Edgar Morin (1996), a transdisciplinaridade apresenta-se como uma abordagem científica que visa a unidade do conhecimento. Desta forma, procura estimular uma nova compreensão da realidade articulando elementos que passam entre, além e através das disciplinas, numa busca de compreensão da complexidade. Outro elemento importante é a importância do saber como modo de reflexão, mediação entre outros elementos, nos levando a pensar e repensar o saber, pois o saber não se perfaz através da acumulação.

Neste sentido, é preciso promover um novo olhar sem que haja uma redução da realidade, se faz necessário que exista uma comunicação que permita distinguir os domínios científicos, operando de maneira enraizada, não se tratando de reduzir o humano a interações físico-químicas, mas reconhecer seus níveis de emergência da realidade. Quando as crianças quilombolas brincam elas resistem, quando demonstram autonomia elas resistem, elas vivem suas infâncias pautadas em suas ancestralidades, elas garantem seus direitos cotidianamente contando com uma rede de pessoas e diversos espaços de aprendizagem dentro de seu território, 
interagindo com os espaço, com adultos e adolescentes e principalmente com seus pares, expressando-se diferentes maneiras e criando novas culturas, novos olhares diante daquilo que já foi construído antes delas.

\section{Projeto de intervenção com os estudantes de ensino fundamental II}

O projeto de intervenção com os estudantes do ensino fundamental teve a intenção de produzir com os jovens, pequenas pesquisas de interesse dos alunos. A ideia inicial era que os estudantes que já trabalhavam com desenvolvimento de projetos na escola pudessem, naquele breve período, desenvolver uma pesquisa sobre temáticas relacionadas a comunidade, a suas identidades e seus interesses como grupo. Nossa intervenção foi de um dia na semana por quatro meses e, seguindo os horários do calendário escolar, a rotina das nossas atividades ficou planejada da seguinte maneira:

\begin{tabular}{|c|c|}
\hline $11 \mathrm{~h}$ & Receber os alunos com rodas de conversas ou atividades \\
\hline $13 \mathrm{~h} 15$ & Intervalo \\
\hline $13 \mathrm{~h} 40$ & Desenvolver os projetos \\
\hline $15 \mathrm{~h} 00$ & Brincadeiras \\
\hline
\end{tabular}

A proposta das brincadeiras seria um intercâmbio, no qual nós iríamos apresentar uma dinâmica ou brincadeira nova para eles e eles também apresentariam alguma brincadeira, jogo ou dinâmica para nós. Mas a proposta principal era o desenvolvimento dos projetos, que já na primeira visita teve seus caminhos traçados, assim como foi relatado no caderno de campo:

Depois do almoço voltamos e conversamos com eles sobre os projetos e quais ideias eles tinham pra fazer, então listamos vários temas de interesse comum no quadro, surgiram várias ideias, e dessas a gente conseguiu dividir 3 temas de interesse: 1- Cabelos: Tudo que os alunos colocaram como interesse em autoestima, autocuidado, estética e coisas relacionadas a imagem do negro acabavam caindo no tema gerador que definimos como cabelo; 2- Quilombo: Tudo que eles listaram que tinha haver com o território, modo de vida, tradições, lugares e que se relacionavam de alguma maneira com a histórias deles ali, nos colocamos como tema gerador de quilombo; 3- Plantas: Houve um grande interesse em fazer uma pesquisa voltada às plantas medicinais da comunidade, por conta que esse projeto já vinha também sendo desenvolvido 
ao longo do ano com eles, mas o interesse ainda era grande sobre a temática que colocamos como Plantas. Depois de agrupar os interesses nesses 3 temas deixamos livre para que eles escolhessem qual grupo que queriam se inserir. Todas as meninas escolheram pesquisar sobre cabelos, e os meninos, que são em maior número, se dividiram pelos 3 grupos. [..] Depois disso cada um ficaria no seu grupo e começaria a desenhar os caminhos da pesquisa. (MOREIRA, Caderno de Campo, 23/06/2017).

Durante nossas visitas os projetos iam se desenvolvendo, no início das escolhas dos projetos se gerou uma pequena polêmica relacionada a conflitos de gênero. O projeto de cabelos ficou formado por todas as meninas da escola e alguns meninos, então alunos dos outros grupos acharam cômico, em um momento inicial, meninos participarem deste projeto, soltando comentários abafados por risadas que aquele seria um "projeto de meninas". Como resposta, um dos alunos, pertencente ao grupo sobre cabelos, ao perceber a chacota dos colegas, respondeu de forma simples e direta: "ué e homem não tem cabelo não?".

Depois desse momento, não presenciamos mais durante as nossas visitas provocações do mesmo gênero. Na visita realizada no mês de setembro de 2017 foram desenvolvidas as atividades pelos alunos do ensino fundamental. Os alunos do Projeto de cabelos, que participaram de uma oficina de turbantes, posteriormente escolheram partes do colégio para tirarem fotografias que os valorizassem, mas que também valorizassem o espaço do colégio, trazendo lindos resultados. Enquanto essa atividade era desenvolvida, era possível ver os estudantes do grupo de ervas medicinais explorando e catalogando as plantas do colégio.

Nossa última visita de 2017 realizada à comunidade veio carregada de emoções, várias atividades aconteceram em conjunto, como a apresentação dos projetos, na qual professores e alunos realizaram uma apresentação do trabalho que havia sido desenvolvido. Nos trabalhos realizados pelos estudantes do ensino fundamental, foi possível perceber que a busca de referências estava na própria comunidade, quanto aos saberes com as plantas, para o que eles buscaram os mais velhos. Quanto ao projeto de cabelo, eles citaram pessoas da comunidade que eram fontes de inspiração, essa experiência nos revelou que o ensino escolar quilombola voltado às suas tradições e valorização da comunidade estava entronizado nos estudantes, era visível a interação dos alunos com o território e com consciência sobre os valores da comunidade. Assim entendemos que:

[...] o processo de humanização requer ser consciente da possibilidade de existência e atuar responsavelmente e conscientemente sobre - e sempre contra - as estruturas e condições sociais que pretendem negar sua possibilidade. A humanização e libertação individual requer a humanização e libertação social, o que implica a conexão entre o subjetivo e o objetivo; quer 
dizer, entre o interiorizado da desumanização e o reconhecimento das estruturas e condições sociais que fazem esta desumanização. (WALSH, 2009, p.33)

A desconstrução de um pensamento eurocêntrico e a construção de um pensamento coletivo e insubmisso precisam de constante reflexão, para isso o trabalho deve ser em conjunto no sentido de instigar o estudante para a sua emancipação epistêmica, em um processo contínuo de aprendizagem e redescobertas. No caso das comunidades quilombolas, essa desconstrução está há séculos em resistência, construindo seus ensinamentos na passagem dos conhecimentos técnicos, culturais e históricos dos mais velhos para os mais novos. O que se caracteriza como inovador e revolucionário é a instituição formal reconhecer a importância desses conhecimentos e também incluir na sua proposta pedagógica e no seu currículo práticas que possibilitem a manutenção desse fazer educacional tradicional.

\section{Projeto de intervenção com os estudantes de Ensino Médio}

Os estudantes do ensino médio realizaram cine-debates como projeto de intervenção. A turma era muito pequena e no planejamento pensamos em algo que pudesse auxiliar no debate crítico sobre relações étnico raciais. $\mathrm{O}$ interessante da atividade foi perceber professores e alunos do Ensino Médio engajados na proposta apresentada com olhares atentos e curiosos. O primeiro filme exibido e debatido foi a Negação do Brasil, documentário que trata a pouca representatividade negra nas novelas brasileiras, protagonizados por atores que deram seus depoimentos sobre esteriótipos e outras questões relacionadas às mídias e o racismo. O segundo cine-debate foi com o filme "Bem-vindo a Marly-Gomont", que conta a história de Seyolo Zantoko, um médico que acabou de se formar em Kinshasa, capital do seu país natal, o Congo. De lá, ele decide partir para uma pequena aldeia francesa, um vilarejo que lhe deu uma imperdível oportunidade de trabalho. Com a sua família ao seu lado, Zantoko embarca na maior jornada de sua vida, onde precisará vencer o preconceito e as barreiras culturais.

Durante as discussões, foi possível perceber a necessidade de se afirmarem enquanto mulheres, negros e, principalmente, enquanto quilombolas, identidades essas que provocam não somente a demarcação social dos sujeitos, mas também suas lutas sociais por direitos. Os estudantes relataram a importância de se colocarem como pertencentes a esse território essencialmente quando vão a cidade, pois ainda enfrentam muitos estereótipos sobre seu modo de vida e também sobre suas características. Essa era a angústia de alunas brancas quilombolas 
com total pertencimento ao território, mas que fora da comunidade não eram consideradas como tal, por um estereótipo racializado e preconceituoso de quem são os quilombolas hoje, quando se tem uma breve noção da sua existência, como é citado a seguir:

Assim como no passado colonial, a identidade quilombola se constrói, ainda atualmente, como uma identidade de luta e resistência: antes contra a captura e a escravidão; hoje, contra a invisibilidade e a negação da existência desses sujeitos enquanto quilombolas (FURTADO, SUCUPIRA e ALVES,2014, p. 112).

Essas questões são muito polêmicas no campo social, pois é necessário reconhecer os efeitos que a globalização e miscigenação provocaram nesta sociedade pós-colonial, onde as diferentes identidades se conflitam em relação ao pertencimento a um determinado lugar, principalmente quando se trata de múltiplas identidades. $\mathrm{O}$ que os jovens relataram é que, em determinados espaços, a identidade quilombola é anulada pela sociedade, pelo imaginário fragilizado de "não existência das comunidades", principalmente nos estados do sul, onde existe um imaginário racista ainda maior de que "não existem negros nessa região", ou que existem pouquíssimos negros habitando o sul brasileiro. Esse pensamento racista ainda opera com força em locais mais afastados dos centros urbanos como os jovens relatam e, nesse contexto, afirmar sua identidade negra e quilombola torna-se cada vez essencial. O que entra em conflito é quanto ao imaginário racializado dos quilombolas, sem entender que as comunidades também sofreram mudanças, sendo assim:

Precisamos vincular as discussões sobre identidade a todos aqueles processos e práticas que têm perturbado o caráter relativamente estabelecido de muitas populações e culturas: os processos de globalização, os quais, eu argumentaria, coincidem com a modernidade, e os processos de migração forçada (ou livre) que têm se tornado um fenômeno global do assim chamado mundo pós-colonial (HALL, 2014, p.108).

As dimensões sociais e pessoais da identidade convivem de maneira dinâmica. O reconhecimento de pertencimento do sujeito frente a valores e conteúdos pertencente à realidade histórico-cultural singular deste contexto, envolvem sua identidade e proporciona que o sujeito se reconheça como quilombola, fazendo parte de um todo. Nesse sentido, foi importante perceber que as estudantes brancas valorizavam sua identidade e origem quilombola, ao mesmo tempo que reconheciam seu privilégio em relação aos estudantes negros. Tal postura se mostrou muito presente durante os debates em relação aos filmes trabalhados e sobre experiências pessoais de cada estudante. 


\section{Considerações finais}

A educação escolar quilombola possui muitas especificidades, pois a própria comunidade torna-se um espaço pedagógico fundamental e central para seus educandos, trazendo pra realidade e pro modo de viver elementos que constroem a subjetividade dos sujeitos, considerando questões que envolvem a cultura de seu território, identidade, diversidade e diferença. É por meio do processo educativo que será possível construir pedagogias efetivas para a valorização da comunidade e da diversidade, articulando os saberes da comunidade com a produção de conhecimento escolar com um panorama emancipador, através da intencionalidade na escola em seu currículo. Nesta perspectiva, ter uma escola em seu território é falar sobre fortalecimento cultural, luta pelo seu território e identidade dos sujeitos através de suas próprias histórias respeitando as suas especificidades.

Diante dessas questões, foi possível concluir que mesmo diante de uma exclusão secular no que diz respeito ao âmbito educacional das comunidades quilombolas, elas desenvolveram e desenvolvem suas próprias pedagogias. Desta forma, provam que o conhecimento formal não se configura como pré-requisito para sujeitos conscientes de si, de suas reivindicações e da identidade que representam. Cada espaço escolar irá expressar seu processo histórico, algo que fica visível desde a entrada da escola, com portões destrancados com uma frase de Nelson Mandela de um lado do muro e informações sobre a lei 10.639 de outro. Neste conjunto, a escola apresenta-se com um fazer coletivo, em que todos da comunidade que a compõem e interagem com o cotidiano escolar, se reconhecem como motivadores e sustentadores de uma escola voltada para o exercício da cidadania e da igualdade.

Os alunos do pré-pós também buscaram referências em seus trabalhos que valorizavam a comunidade, e durante as apresentações os alunos foram se reconhecendo nos espaços que estavam sendo expostos, assim como também foram reconhecendo seus pares, como referenciar seus anciões como fonte histórica de conhecimento. Essa experiência nos aproximou mais da comunidade e também trouxe mais enriquecimento para nossas pesquisas individuais e nossos olhares diante das comunidades quilombolas, de modo que podemos registar o crescimento do grupo para além das pesquisas, nas suas construções de amizade, respeito e interação com a comunidade. 


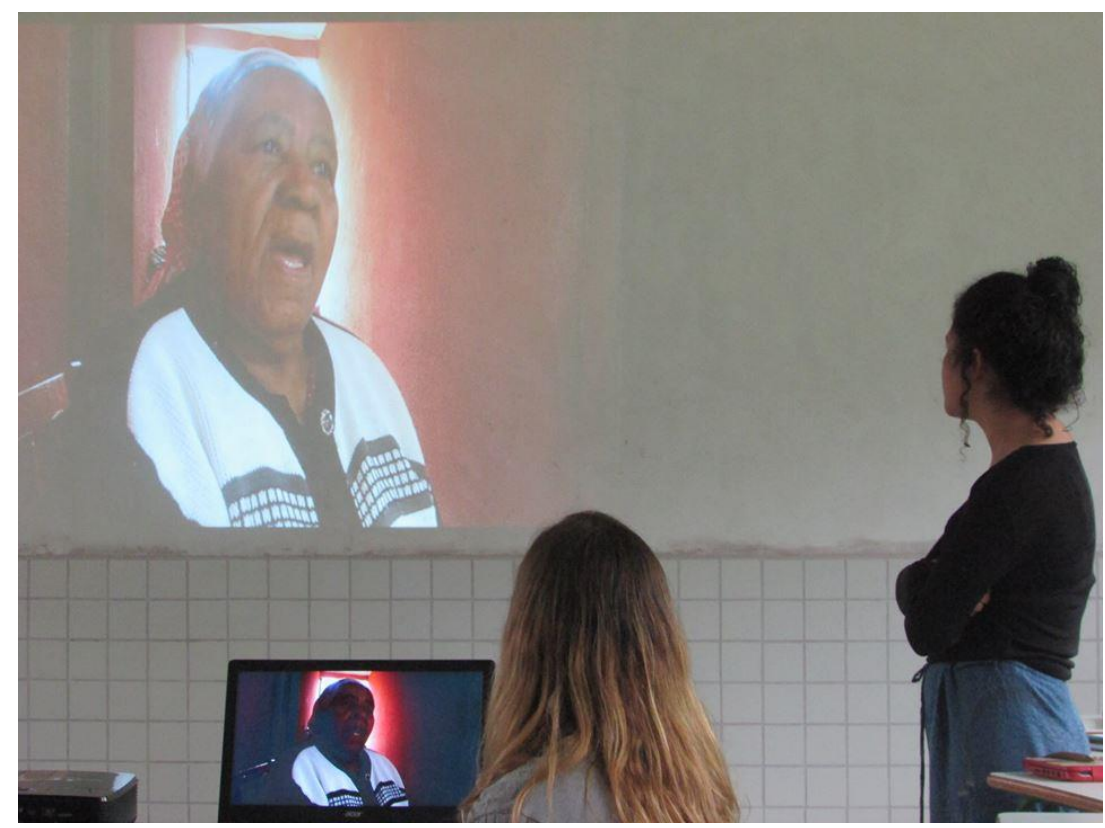

FONTE: Sanciaray Yarha Silva da Rosa (Setembro de 2017)

O colégio vem mostrando que, apesar de todas as barreiras e desafios, é possível construir uma gestão democrática, com interlocutores que dialogam e produzem respostas, relacionando-se com diferentes momentos históricos, considerando as vivências de seus educandos, integrando os saberes da comunidade com seu currículo, reconhecendo o território como parte integrante do processo educativo. Mostram, assim, a possibilidade de construir uma educação libertadora, que busca quebrar com os padrões hegemônicos e engajada na luta antirracista, além das lutas de direito ao seu território.

De modo geral o projeto trouxe novas perspectivas sobre a educação. Na prática, pudemos ver aquilo que muitos chamam de utopia, uma educação pública e de qualidade, comprometida com as lutas e temáticas que façam sentido aos estudantes, os reconhecendo como produtores de cultura, percebendo também os desafios que devem ser rompidos enquanto instituição, mas buscando soluções coletivas, com uma gestão democrática. À João Surá somos gratas pelas experiências que ampliaram a nossa visão de educação, entendendo que ela está presente no ambiente educacional, mas que existe algo muito maior ao redor dela acontecendo, e que caminhando juntas podemos ajudar a construir um país melhor, com pessoas comprometidas não apenas com o seu próprio território, mas com tudo aquilo que as constituem. 


\section{Referências}

ASSOCIAÇÃO BRASILEIRA DE ANTROPOLOGIA - ABA. Documento do Grupo de Trabalho sobre Comunidades Negras Rurais (Rio de Janeiro, 17-18 de outubro de 1994).Boletim Informativo NUER - Núcleo de Estudos sobre Identidade e Relações Interétnicas / Fundação Cultural Palmares - v. 1, Florianópolis: UFSC, 1997, pp. 81-82. Disponível em: <http://nuer.ufsc.br/files/2014/04/m-mgpefhgnff_boletim_nuer_1.pdf>. Acesso em: 11 mar. 2018

BORBA, C. A. MOREIRA, F. Educação Escolar Quilombola e a Coordenação Pedagógica no Colégio Diogo Ramos. in POLI, J. P. DIAS, L. R. FERREIRA, V. M. R. Coordenação Pedagógica a Formação e os Desafios da Prática nas Escolas. Curitiba: Appris, 2018

BRASIL. Ministério de Educação e Cultura. LDB - Lei no 9394/96, de 20 de dezembro de 1996. Estabelece as diretrizes e bases da Educação Nacional. Brasília : MEC, 1996.

CAMPOS, C. M., GALLINARI, S, T. A educação escolar quilombola e as escolas quilombolas no Brasil. Revista Nera, ano 20, nº. 35, Janeiro/Abril de 2017.

MATTOS, C. L. G. A abordagem etnográfica na investigação científica. In MATTOS, CLG., CASTRO, PA., orgs. Etnografia e educação: conceitos e usos. Campina Grande: EDUEPB, 2011.

SUPERINTENDÊNCIA DA EDUCAÇÃO, Secretaria de Estado da Educação. Educação Escolar quilombola: pilões, peneiras e conhecimento escolar. Cadernos Temáticos da Diversidade. Curitiba: SEED, 2010.

FREIRE, P. Educação Como Prática da Liberdade. Rio de Janeiro: Paz e Terra, 1996.

FURTADO, M. B., SUCUPIRA, R. L. ALVES, C. B. Cultura, identidade e subjetividade quilombola: uma leitura a partir da psicologia cultural. Psicologia \& Sociedade, 26(I), 2014, p.106-115.

GARCÉS, F. Las políticas del conocimiento y la colonialidad lingüística y epistémica. in: CASTRO-GÓMEZ, S. GROSFOGUEL R. El giro decolonial Reflexiones para una diversidad epistémica más allá del capitalismo global. Bogotá: Siglo del Hombre Editores; Universidad Central, Instituto de Estudios Sociales Contemporáneos y Pontificia Universidad Javeriana, Instituto Pensar, 2007, p. 217-241.

HALL, S. Quem Precisa da Identidade? in. SILVA, T. T. HALL, S. WOODWARD, K. Identidade e diferença: a perspectiva dos estudos culturais. Petropolis: Vozes, 2014.

MORIN, E. A antiga e a nova transdisciplinaridade. In: MORIN, E. Ciência com consciência. Rio de Janeiro: Bertrand Brasil, 1996. p.135-140.

QUIJANO, A. Colonialidad del poder y clasificación social . in: CASTRO-GÓMEZ, S. GROSFOGUEL R. El giro decolonial Reflexiones para una diversidad epistémica más allá del capitalismo global. Bogotá: Siglo del Hombre Editores; Universidad Central, Instituto de Estudios Sociales Contemporáneos y Pontificia Universidad Javeriana, Instituto Pensar, 2007, p. 93-125. 
ROCHA, M. S. SILVA, J. B. S. Reflexões sobre educação escolar quilombola. São Paulo, v.34, n.68, p.79-91, 2016.

WALSH, C. Interculturalidade Crítica e Pedagogia Decolonial: in-surgir, re-existir e re-viver. in: CANDAU, V. M. Educação Intercultural na América Latina: entre concepções, tensões e proposta. Rio de Janeiro: Letras, 2009, p.12-42.

Artigo recebido em 08/04/2019. Aceito para publicação em 17/07/2019. 